\title{
Approximation of a Common Element of the Fixed Point Sets of Multivalued Strictly Pseudocontractive-Type Mappings and the Set of Solutions of an Equilibrium Problem in Hilbert Spaces
}

\author{
F. O. Isiogugu ${ }^{1,2}$ \\ ${ }^{1}$ School of Mathematics, Statistics and Computer Sciences, University of KwaZulu-Natal, Westville Campus, \\ Durban 4000, South Africa \\ ${ }^{2}$ Department of Mathematics, University of Nigeria, Nsukka 410001, Nigeria
}

Correspondence should be addressed to F. O. Isiogugu; felicia.isiogugu@unn.edu.ng

Received 8 December 2015; Revised 14 February 2016; Accepted 17 February 2016

Academic Editor: Simeon Reich

Copyright (C) 2016 F. O. Isiogugu. This is an open access article distributed under the Creative Commons Attribution License, which permits unrestricted use, distribution, and reproduction in any medium, provided the original work is properly cited.

\begin{abstract}
The strong convergence of a hybrid algorithm to a common element of the fixed point sets of multivalued strictly pseudocontractivetype mappings and the set of solutions of an equilibrium problem in Hilbert spaces is obtained using a strict fixed point set condition. The obtained results improve, complement, and extend the results on multivalued and single-valued mappings in the contemporary literature.
\end{abstract}

\section{Introduction}

Let $X$ be a nonempty set and let $T: X \rightarrow X$ be a map. A point $x \in X$ is called a fixed point of $T$ if $x=T x$. If $T: X \rightarrow 2^{X}$ is a multivalued map then $x$ is a fixed point of $T$ if $x \in T x$. If $T x=\{x\}$ then $x$ is called a strict fixed point of $T$. The set $F(T)=\{x \in D(T): x \in T x\}$ (resp., $F(T)=\{x \in D(T): x=$ $T x\}$ ) is called the fixed point set of multivalued (resp., singlevalued) map $T$, while the set $F_{s}(T)=\{x \in D(T): T x=\{x\}\}$ is called the strict fixed point set of $T$.

Let $X$ be a normed space. A subset $K$ of $X$ is called proximinal if for each $x \in X$ there exists $k \in K$ such that

$$
\|x-k\|=\inf \{\|x-y\|: y \in K\}=d(x, K) .
$$

It is known that every closed convex subset of a uniformly convex Banach space is proximinal. We will denote the family of all nonempty closed and bounded subsets of $X$ by $\mathrm{CB}(X)$, the family of all nonempty subsets of $X$ by $2^{X}$, and the family of all proximinal subsets of $X$ by $P(X)$, for a nonempty set $X$.

Let $H$ denote the Hausdorff metric induced by the metric $d$ on $X$; that is, for every $A, B \in \mathrm{CB}(X)$,

$$
H(A, B)=\max \left\{\sup _{a \in A} d(a, B), \sup _{b \in B} d(b, A)\right\} .
$$

Let $X$ be a normed space. Let $T: D(T) \subseteq X \rightarrow 2^{X}$ be a multivalued mapping on $X$. A multivalued mapping $T$ : $D(T) \subseteq X \rightarrow 2^{X}$ is called L-Lipschitzian if there exists $L \geq 0$ such that for all $x, y \in D(T)$

$$
H(T x, T y) \leq L\|x-y\| .
$$

In (3) if $L \in[0,1) T$ is said to be a contraction while $T$ is nonexpansive if $L=1 . T$ is called quasi-nonexpansive if $F(T)=\{x \in D(T): x \in T x\} \neq \emptyset$ and for all $p \in F(T)$,

$$
H(T x, T p) \leq\|x-p\| .
$$

Clearly every nonexpansive mapping with nonempty fixed point set is quasi-nonexpansive. $T$ is said to be $k$-strictly pseudocontractive-type of Isiogugu [1] if there exists $k \epsilon$ $(0,1)$ such that, given any pair $x, y \in D(T)$ and $u \in T x$, there exists $v \in T y$ satisfying $\|u-v\| \leq H(T x, T y)$ and

$$
H^{2}(T x, T y) \leq\|x-y\|^{2}+k\|x-u-(y-v)\|^{2} .
$$

If $k=1$ in (5), $T$ is said to be pseudocontractive-type, while $T$ is nonexpansive-type if $k=0$. Every multivalued nonexpansive mapping $T: D(T) \subseteq X \rightarrow P(X)$ is nonexpansive-type. In a real Hilbert space $H, T: D(T) \subseteq$ 
$H \rightarrow \mathrm{CB}(H)$ is said to be $k$-strictly pseudocontractive of Chidume et al. [2] if there exists $k \in(0,1)$ such that for all $x, y \in D(T)$

$$
\begin{aligned}
& H^{2}(T x, T y) \leq\|x-y\|^{2}+k \| x-u-(y-v) \|^{2}, \\
& \forall u \in T x, v \in T y .
\end{aligned}
$$

If $k=1, T$ is said to be pseudocontractive. It is easy to see that every $k$-strictly pseudocontractive mapping $T: D(T) \subseteq$ $H \rightarrow P(H)$ is $k$-strictly pseudocontractive-type.

Let $H$ be a real Hilbert space with inner product $\langle\cdot, \cdot\rangle$ and norm $\|\cdot\|$, respectively, and let $C$ be a nonempty closed convex subset of $H$. Given an operator $A: H \rightarrow H$ and a closed convex set $C$, the variational inequality problem is the problem of finding $x^{*} \in C$ such that $\left\langle x-x^{*}, A\left(x^{*}\right)\right\rangle \geq 0$, for all $x \in C$. This variational inequality problem is usually denoted as $\operatorname{VIP}(A, C)$.

Let $F: C \times C \rightarrow \mathbb{R}$ be a bifunction, where $\mathbb{R}$ is the set of real numbers. The equilibrium problem for $F: C \times C \rightarrow \mathbb{R}$ is to find $x \in C$ such that

$$
F(x, y) \geq 0 \quad \forall y \in C .
$$

The set of solutions of (7) is denoted by $\operatorname{EP}(F)$. Several algorithms were introduced by authors for approximating solutions of equilibrium problems for a bifunction (or finite family of bifunctions) (see, e.g., [3] and references therein). Given a mapping $A: C \rightarrow H$, let $F(x, y)=\langle A x, y-x\rangle$ for all $x, y \in C$; then $z \in \operatorname{EP}(F)$ if and only if $\langle A z, y-z\rangle \geq 0$ for all $y \in C$; that is, $z$ is a solution of the variational inequality $\operatorname{VIP}(A, C)$. Numerous problems in physics, optimization, and economics are reduced to the problem of finding the solutions of (7) (see, e.g., [4-6] and the references therein).

The purpose of this work is to first establish closed and convexity property for a strict fixed point set of a multivalued strictly pseudocontractive-type mappings. Second, establish with a strict fixed point set condition a strong convergence of a hybrid algorithm to a common element of the fixed point sets of two multivalued strictly pseudocontractive-type mappings and the set of solutions of an equilibrium problem in Hilbert spaces. The obtained results extend, complement, and improve the results on equilibrium problems as well as multivalued and single-valued mappings in the contemporary literature.

\section{Preliminaries}

In the sequel, we will need the following definitions and lemmas.

Definition 1. Let $T: X \rightarrow 2^{X}$ be a multivalued mapping; for each $x \in X, P_{T} x$ is defined by

$$
P_{T}(x)=\{y \in T x:\|x-y\|=d(x, T x)\} .
$$

For solving the equilibrium problems for a bifunction $F: C \times$ $C \rightarrow \mathbb{R}$, let us assume that $F$ satisfies the following conditions:

(A1) $F(x, x)=0$ for all $x \in C$.
(A2) $F$ is monotone; that is, $F(x, y)+F(y, x) \leq 0$, for all $x, y \in C$.

(A3) For each $x, y, z \in C, \lim _{t \downarrow 0} F(t z+(1-t) x, y) \leq F(x, y)$.

(A4) For each $x \in C, y \mapsto F(x, y)$ is convex and lower semicontinuous.

Lemma 2 (see [4]). Let $C$ be a nonempty closed convex subset of a real Hilbert space $H$ and $F: C \times C \rightarrow \mathbb{R}$ a bifunction satisfying (A1)-(A4). Let $r>0$ and $x \in H$. Then, there exists $z \in C$ such that

$$
F(z, y)+\frac{1}{r}\langle y-z, z-x\rangle \geq 0, \quad \forall y \in C .
$$

Lemma 3 (see [6]). Let $C$ be a nonempty closed convex subset of a real Hilbert space $H$. Assume that $F: C \times C \rightarrow \mathbb{R}$ satisfying (A1)-(A4). Let $r>0$ and $x \in H$. Define $T_{r}: H \rightarrow 2^{C}$ by

$$
\begin{aligned}
T_{r}(x)=\left\{z \in C: F(z, y)+\frac{1}{r}\langle y-z, z-x\rangle\right. & \geq 0\}, \\
& \forall y \in C .
\end{aligned}
$$

Then the following hold:

(1) $T_{r}$ is single valued.

(2) $T_{r}$ is firmly nonexpansive; that is, for any $x, y \in H$, $\left\|T_{r} x-T_{r} y\right\|^{2} \leq\left\langle T_{r} x-T_{r} y, x-y\right\rangle$.

(3) $F\left(T_{r}\right)=\mathrm{EP}(F)$.

(4) $\mathrm{EP}(F)$ is closed and convex.

Lemma 4 (see [7]). Let $C$ be a nonempty closed convex subset of a real Hilbert space $H$ and $F: C \times C \rightarrow \mathbb{R}$ a bifunction satisfying (A1)-(A4). Let $r>0$ and $x \in H$. Then for all $x \in H$ and $p \in F\left(T_{r}\right)$

$$
\left\|p-T_{r} x\right\|^{2}+\left\|T_{r} x-x\right\|^{2} \leq\|p-x\|^{2} .
$$

Lemma 5. Let $H$ be a real Hilbert space, and let $C$ be a nonempty closed convex subset of $H$. Let $P_{C}$ be the convex projection onto $C$. Then, convex projection is characterized by the following relations:

(i) $x^{*}=P_{C}(x) \Leftrightarrow\left\langle x-x^{*}, y-x^{*}\right\rangle \leq 0$, for all $y \in C$.

(ii) $\left\|x-P_{C} x\right\|^{2} \leq\|x-y\|^{2}-\left\|y-P_{C} x\right\|^{2}$.

(iii) $\left\|x-P_{C} y\right\|^{2} \leq\|x-y\|^{2}-\left\|P_{C} y-y\right\|^{2}$.

\section{Main Results}

Proposition 6. Let $K$ be a nonempty subset of a real Hilbert space $H$. And let $T: K \rightarrow P(K)$ be a $k$-strictly pseudocontractive-type mapping such that $F_{s}(T)$ is nonempty. Then $F_{s}(T)$ is closed and convex.

Proof. Let $\left\{x_{n}\right\}_{n=1}^{\infty} \subseteq F_{s}(T)$ such that $\left\{x_{n}\right\}_{n=1}^{\infty}$ converges to $x \in$ $K$. We show that $x \in F_{s}(T)$. Let $u \in T x$ be arbitrary:

$$
\begin{aligned}
\|x-u\| & \leq\left\|x-x_{n}\right\|+\left\|x_{n}-u\right\| \\
& \leq\left\|x-x_{n}\right\|+H\left(T x_{n}, T x\right) \\
& \leq\left\|x-x_{n}\right\|+\left\|x-x_{n}\right\|+\sqrt{k}\|x-u\| .
\end{aligned}
$$


Taking limits as $n \rightarrow \infty$, we have that $\|x-u\| \leq \sqrt{k}\|x-u\|$. Hence, $x=u \in T x$. Since $u$ was arbitrary, we have that $T x=$ $\{x\}$.

We now prove that $F(T)$ is convex. Let $p_{1}, p_{2} \in F(T)$ and $z=\alpha p_{1}+(1-\alpha) p_{2}$ and then $z-p_{1}=(1-\alpha)\left(p_{2}-p_{1}\right)$ and $z-p_{2}=\alpha\left(p_{1}-p_{2}\right)$ :

$$
\begin{aligned}
d^{2}(z, T z) \leq & \|z-u\|^{2}, \quad \forall u \in T z \\
= & \left\|\alpha p_{1}+(1-\alpha) p_{2}-u\right\|^{2} \\
= & \alpha\left\|p_{1}-u\right\|^{2}+(1-\alpha)\left\|p_{2}-u\right\|^{2} \\
& -\alpha(1-\alpha)\left\|p_{2}-p_{1}\right\|^{2} .
\end{aligned}
$$

Now, $k$-strictly pseudocontractive-type condition on $T$ and a strict fixed point condition on $p_{1}$ and $p_{2}$ imply that, for all $u \in T z,\left\|u-p_{1}\right\| \leq H\left(T z, T p_{1}\right)$ and $H^{2}\left(T z, T p_{1}\right) \leq\left[\left\|z-p_{1}\right\|^{2}+\right.$ $\left.k\|z-u\|^{2}\right]$. and $\left\|u-p_{2}\right\| \leq H\left(T z, T p_{2}\right)$ and $H^{2}\left(T z, T p_{2}\right) \leq$ $\left[\left\|z-p_{2}\right\|^{2}+k\|z-u\|^{2}\right]$. It then follows that

$$
\begin{aligned}
d^{2}(z, T z) \leq & \|u-z\|^{2} \\
= & \alpha\left\|p_{1}-u\right\|^{2}+(1-\alpha)\left\|p_{2}-u\right\|^{2} \\
& -\alpha(1-\alpha)\left\|p_{2}-p_{1}\right\|^{2} \\
\leq & \alpha H^{2}\left(T z, T p_{1}\right)+(1-\alpha) H^{2}\left(T z, T p_{2}\right) \\
& -\alpha(1-\alpha)\left\|p_{1}-p_{2}\right\|^{2} \\
\leq & \alpha\left[\left\|z-p_{1}\right\|^{2}+k\|z-u\|^{2}\right] \\
& +(1-\alpha)\left[\left\|z-p_{2}\right\|^{2}+k\|z-u\|^{2}\right] \\
& -\alpha(1-\alpha)\left\|p_{1}-p_{2}\right\|^{2} .
\end{aligned}
$$

In particular, for each $u \in P_{T} z$,

$$
\begin{aligned}
d^{2}(z, T z) \leq & \alpha\left[\left\|z-p_{1}\right\|^{2}+k d^{2}(z, T z)\right] \\
& +(1-\alpha)\left[\left\|z-p_{2}\right\|^{2}+k d^{2}(z, T z)\right] \\
& -\alpha(1-\alpha)\left\|p_{1}-p_{2}\right\|^{2} \\
= & \left\|\alpha p_{1}+(1-\alpha) p_{2}-z\right\|^{2}+k d^{2}(z, T z) \\
= & k d^{2}(z, T z) .
\end{aligned}
$$

Hence, $d(z, T z)=0$. Since $T z$ is proximinal, there exists $w \in$ $T z$ such that $\|w-z\|=0$; consequently, $z \in T z$. Also, if $v \in T z$, then

$$
\begin{aligned}
\|v-z\|^{2}= & \left\|v-\alpha p_{1}+(1-\alpha) p_{2}\right\|^{2} \\
\leq & \alpha\left[\left\|z-p_{1}\right\|^{2}+k\|z-v\|^{2}\right] \\
& +(1-\alpha)\left[\left\|z-p_{2}\right\|^{2}+k\|z-v\|^{2}\right] \\
& -\alpha(1-\alpha)\left\|p_{1}-p_{2}\right\|^{2}=k\|z-v\|^{2}
\end{aligned}
$$

which shows that $z=v$. Thus, $T z=\{z\}$.
We now prove a strong convergence of multivalued version of the hybrid algorithm considered in [8] to a common element of the set of fixed points of two $k$-strictly pseudocontractive-type mappings and the set of solutions of an equilibrium problem in Hilbert spaces. As a corollary, we obtain a hybrid algorithm for finding common elements of the set of fixed points of two multivalued strictly pseudocontractive mappings of [2] and the set of solutions of an equilibrium problem, with a strict fixed point set condition.

Theorem 7. Let $C$ be a nonempty closed convex subset of a real Hilbert space $H$, let $f: C \times C \rightarrow \mathbb{R}$ be a bifunction satisfying (A1)-(A4), and let $S, T: C \rightarrow P(C)$ be two strictly pseudocontractive-type mappings with contractive coefficients $\lambda_{1}$ and $\lambda_{2}$, respectively, such that $\mathbb{F}=F_{s}(T) \cap F_{s}(S) \cap \mathrm{EP}(f) \neq \emptyset$. Let $\left\{x_{n}\right\}$ be a sequence generated from an arbitrary $x_{0} \in C$ as follows:

$$
\begin{aligned}
& x_{0} \in H, \\
& C_{1}=C, \\
& x_{1}=P_{C} x_{0}, \\
& y_{n}=\alpha_{n} x_{n}+\left(1-\alpha_{n}\right)\left[\beta_{n} v_{n}+\left(1-\beta_{n}\right) z_{n}\right], \\
& u_{n} \in C \text { such that } \\
& F\left(u_{n}, y\right)+\frac{1}{r_{n}}\left\langle y-u_{n}, u_{n}-y_{n}\right\rangle \geq 0, \quad \forall y \in C, \\
& C_{n+1}=\left\{z \in C_{n}:\left\|z-u_{n}\right\|^{2} \leq\left\|z-x_{n}\right\|^{2}\right\}, \\
& x_{n+1}=P_{C_{n+1}} x_{0},
\end{aligned}
$$

where $v_{n} \in T x_{n}$ and $z_{n} \in S x_{n} .\left\{\alpha_{n}\right\}_{n=1}^{\infty}$ and $\left\{\beta_{n}\right\}_{n=1}^{\infty}$ are sequences in $[0,1]$ satisfying

(i) $\alpha_{n} \geq \max \left\{\lambda_{1}, \lambda_{2}\right\}$

(ii) $\lim _{\inf _{n \rightarrow \infty}}\left(1-\alpha_{n}\right)\left(1-\beta_{n}\right)\left(\alpha_{n}-\lambda_{1}\right)>0$ and $\lim \inf _{n \rightarrow \infty}\left(1-\alpha_{n}\right)\left(\alpha_{n}-\lambda_{2}\right) \beta_{n}>0$,

(iii) $\left\{r_{n}\right\} \subset[a, \infty)$ for some $a>0$

Then $\left\{x_{n}\right\}$ converges strongly to $p \in P_{\mathbb{F}} x_{0}$.

Proof. Observe that $C_{n}$ is closed and convex for all $n \geq 1$; therefore $P_{C_{x_{n}+1}} x_{0}$ is well defined and note that $u_{n}=T_{r_{n}} y_{n}$. Next we show that $\mathbb{F} \subset C_{n}$, for all $n \geq 1$. $\mathbb{F} \subset C_{1}=C$ is obvious. Suppose $\mathbb{F} \subset C_{k}$, set $w_{n}=\beta_{n} v_{n}+\left(1-\beta_{n}\right) z_{n}$, and then using Lemma 3, for all $q \in \mathbb{F}$, we have

$$
\begin{aligned}
& \left\|q-u_{k}\right\|^{2}=\left\|q-T_{r_{k}} y_{k}\right\|^{2} \leq\left\|q-y_{k}\right\|^{2} \\
& =\left\|q-\left[\alpha_{k} x_{k}+\left(1-\alpha_{k}\right)\left[\beta_{k} v_{k}+\left(1-\beta_{k}\right) z_{k}\right]\right]\right\|^{2} \\
& =\left\|q-\left[\alpha_{k} x_{k}+\left(1-\alpha_{k}\right) w_{k}\right]\right\|^{2} \\
& =\alpha_{k}\left\|x_{k}-q\right\|^{2}+\left(1-\alpha_{k}\right)\left\|w_{k}-q\right\|^{2} \\
& \quad-\alpha_{k}\left(1-\alpha_{k}\right)\left\|x_{k}-w_{k}\right\|^{2} .
\end{aligned}
$$


Also,

$$
\begin{aligned}
\left\|w_{k}-q\right\|^{2}= & \left\|\beta_{k} v_{k}+\left(1-\beta_{k}\right) z_{k}-q\right\|^{2} \\
= & \beta_{k}\left\|v_{k}-q\right\|^{2}+\left(1-\beta_{k}\right)\left\|z_{k}-q\right\|^{2} \\
& -\beta_{k}\left(1-\beta_{k}\right)\left\|v_{k}-z_{k}\right\|^{2} .
\end{aligned}
$$

Using (19) we obtain from (18) that

$$
\begin{aligned}
& \left\|q-u_{k}\right\|^{2} \\
& \leq \alpha_{k}\left\|x_{k}-q\right\|^{2}+\left(1-\alpha_{k}\right) \beta_{k}\left\|v_{k}-q\right\|^{2} \\
& +\left(1-\alpha_{k}\right)\left(1-\beta_{k}\right)\left\|z_{k}-q\right\|^{2} \\
& -\left(1-\alpha_{k}\right) \beta_{k}\left(1-\beta_{k}\right)\left\|v_{k}-z_{k}\right\|^{2} \\
& -\alpha_{k}\left(1-\alpha_{k}\right)\left\|x_{k}-w_{k}\right\|^{2} \\
& \leq \alpha_{k}\left\|x_{k}-q\right\|^{2}+\left(1-\alpha_{k}\right) \beta_{k} H^{2}\left(T x_{k}, T q\right) \\
& +\left(1-\alpha_{k}\right)\left(1-\beta_{k}\right) H^{2}\left(S x_{k}, T q\right) \\
& -\left(1-\alpha_{k}\right) \beta_{k}\left(1-\beta_{k}\right)\left\|v_{k}-z_{k}\right\|^{2} \\
& -\alpha_{k}\left(1-\alpha_{k}\right)\left\|x_{k}-w_{k}\right\|^{2} \\
& \leq \alpha_{k}\left\|x_{k}-q\right\|^{2} \\
& +\left(1-\alpha_{k}\right) \beta_{k}\left[\left\|x_{k}-q\right\|^{2}+\lambda_{2}\left\|x_{k}-v_{k}\right\|^{2}\right] \\
& +\left(1-\alpha_{k}\right)\left(1-\beta_{k}\right)\left[\left\|x_{k}-q\right\|^{2}+\lambda_{1}\left\|x_{k}-z_{k}\right\|^{2}\right] \\
& -\left(1-\alpha_{k}\right) \beta_{k}\left(1-\beta_{k}\right)\left\|v_{k}-z_{k}\right\|^{2} \\
& -\alpha_{k}\left(1-\alpha_{k}\right)\left\|x_{k}-w_{k}\right\|^{2} .
\end{aligned}
$$

Also,

$$
\begin{aligned}
\left\|x_{k}-w_{k}\right\|^{2}= & \left\|x_{k}-\left[\beta_{k} v_{k}+(1-\beta)_{k} z_{k}\right]\right\|^{2} \\
= & \beta_{k}\left\|x_{k}-v_{k}\right\|^{2}+\left(1-\beta_{k}\right)\left\|x_{k}-z_{k}\right\|^{2} \\
& -\beta_{k}\left(1-\beta_{k}\right)\left\|v_{k}-z_{k}\right\|^{2} .
\end{aligned}
$$

Using (21) we obtain from (20) that

$$
\begin{aligned}
& \left\|q-u_{k}\right\|^{2} \leq\left[\alpha_{k}+\left(1-\alpha_{k}\right) \beta_{k}+\left(1-\alpha_{k}\right)\left(1-\beta_{k}\right)\right] \\
& \cdot\left\|x_{k}-q\right\|^{2}+\left[\left(1-\alpha_{k}\right) \beta_{k} \lambda_{2}-\alpha_{k}\left(1-\alpha_{k}\right) \beta_{k}\right] \\
& \cdot\left\|x_{k}-v_{k}\right\|^{2} \\
& +\left[\left(1-\alpha_{k}\right)\left(1-\beta_{k}\right) \lambda_{1}-\alpha_{k}\left(1-\alpha_{k}\right)\left(1-\beta_{k}\right)\right] \\
& \cdot\left\|x_{k}-z_{k}\right\|^{2} \\
& +\left[\left(1-\alpha_{k}\right)\left(1-\beta_{k}\right) \beta_{k} \alpha_{k}-\left(1-\alpha_{k}\right)\left(1-\beta_{k}\right) \beta_{k}\right] \\
& \cdot\left\|v_{k}-z_{k}\right\|^{2}=\left\|x_{k}-q\right\|^{2}-\beta_{k}\left(1-\alpha_{k}\right)\left(\alpha_{k}-\lambda_{2}\right) \\
& \cdot\left\|x_{k}-v_{k}\right\|^{2}-\left(1-\alpha_{k}\right)\left(1-\beta_{k}\right)\left(\alpha_{k}-\lambda_{1}\right) \\
& \cdot\left\|x_{k}-z_{k}\right\|^{2}-\left(1-\alpha_{k}\right)^{2}\left(1-\beta_{k}\right) \beta_{k}\left\|v_{k}-z_{k}\right\|^{2} \\
& \leq\left\|x_{k}-q\right\|^{2} .
\end{aligned}
$$

This shows that $q \in C_{k+1}$. It then follows that $\mathbb{F} \subseteq C_{n}$ for all $n \geq 1$. From $x_{n}=P_{C_{n}} x_{0}$ we have from Lemma 5(i) that

$$
\left\langle x_{n}-y, x_{0}-x_{n}\right\rangle \geq 0, \quad \forall y \in C_{n} .
$$

Since $\mathbb{F} \subseteq C_{n}$ for all $n \geq 1$, we have

$$
\left\langle x_{n}-q, x_{0}-x_{n}\right\rangle \geq 0, \quad \forall q \in F .
$$

Using Lemma 5(ii) we obtain

$$
\begin{aligned}
\left\|x_{n}-x_{0}\right\|^{2} & =\left\|P_{C_{n}} x_{0}-x_{0}\right\|^{2} \leq\left\|x_{0}-q\right\|^{2}-\left\|q-x_{n}\right\|^{2} \\
& \leq\left\|x_{0}-q\right\|^{2},
\end{aligned}
$$

for each $q \in \mathbb{F} \subset C_{n}$ and for all $n \geq 1$. Consequently the sequence $\left\{x_{n}\right\}$ is bounded, and so are $\left\{z_{n}\right\}$ and $\left\{v_{n}\right\}$. Furthermore, since $x_{n}=P_{C_{n}} x_{0}$ and $x_{n+1}=P_{C_{n+1}} x_{0} \in$ $C_{n+1} \subset C_{n}$ then from definition of $P_{C}$ we have $\left\|x_{n}-x_{0}\right\| \leq$ $\left\|x_{n+1}-x_{0}\right\|$ for all $n \geq 1$. Therefore the sequence $\left\{\left\|x_{n}-x_{0}\right\|\right\}$ is nondecreasing. It then follows that $\lim _{n \rightarrow \infty}\left\|x_{n}-x_{0}\right\|$ exists. From the construction of $C_{n}$ we have that $C_{m} \subset C_{n}$ and $x_{m}=P_{C_{m}} x_{0} \in C_{n}$ for any integer $m \geq n$. It also follows from Lemma 5(iii) that

$$
\begin{aligned}
\left\|x_{m}-x_{n}\right\|^{2} & =\left\|x_{m}-P_{C_{n}} x_{0}\right\|^{2} \\
& \leq\left\|x_{m}-x_{0}\right\|^{2}-\left\|P_{C_{n}} x_{0}-x_{0}\right\|^{2} \\
& =\left\|x_{m}-x_{0}\right\|^{2}-\left\|x_{n}-x_{0}\right\|^{2} .
\end{aligned}
$$

Letting $m, n \rightarrow \infty$ in (26), we have $\left\|x_{m}-x_{n}\right\| \rightarrow 0$. Hence $\left\{x_{n}\right\}$ is a Cauchy sequence. Since $H$ is Hilbert and $C$ is closed and convex we can assume that $x_{n} \rightarrow p \in C$ as $n \rightarrow \infty$; that is, $\lim _{n \rightarrow \infty}\left\|x_{n}-p\right\|=0$. We now show that $p \in F(S)$. In particular when $m=n+1$ in (26) we obtain

$$
\lim _{n \rightarrow \infty}\left\|x_{n+1}-x_{n}\right\|=0 .
$$


Also, since $x_{n+1} \in C_{n+1}$, we obtain

$$
\left\|x_{n+1}-u_{n}\right\| \leq\left\|x_{n+1}-x_{n}\right\| .
$$

It then follows from (27) that

$$
\lim _{n \rightarrow \infty}\left\|x_{n+1}-u_{n}\right\|=0 .
$$

Combining (27) and (29) we obtain

$$
\lim _{n \rightarrow \infty}\left\|x_{n}-u_{n}\right\|=0 .
$$

It follows from $\lim _{n \rightarrow \infty}\left\|x_{n}-p\right\|=0$ and (30) that

$$
\lim _{n \rightarrow \infty}\left\|u_{n}-p\right\|=0
$$

Setting $n=k$ in (22) we have

$$
\begin{aligned}
\left\|u_{n}-q\right\|^{2} \leq & \left\|x_{n}-q\right\|^{2} \\
& -\beta_{n}\left(1-\alpha_{n}\right)\left(\alpha_{n}-\lambda_{2}\right)\left\|x_{n}-v_{n}\right\|^{2} \\
& -\left(1-\alpha_{n}\right)\left(1-\beta_{n}\right)\left(\alpha_{n}-\lambda_{1}\right)\left\|x_{n}-z_{n}\right\|^{2} \\
& -\left(1-\alpha_{n}\right)^{2}\left(1-\beta_{n}\right) \beta_{n}\left\|v_{n}-z_{n}\right\|^{2} .
\end{aligned}
$$

Observe that

$$
\begin{aligned}
\| q & -x_{n}\left\|^{2}-\right\| q-u_{n} \|^{2} \\
& =\left\|x_{n}\right\|^{2}-\left\|u_{n}\right\|^{2}-2\left\langle q, x_{n}-u_{n}\right\rangle \\
& \leq\left\|x_{n}-u_{n}\right\|\left(\left\|x_{n}\right\|+\left\|u_{n}\right\|\right)+\|q\|\left\|x_{n}-u_{n}\right\| .
\end{aligned}
$$

It then follows from (30) that

$$
\lim _{n \rightarrow \infty}\left\|q-x_{n}\right\|-\left\|q-u_{n}\right\|=0
$$

Using $\lim \inf _{n \rightarrow \infty}\left(1-\alpha_{n}\right)\left(1-\beta_{n}\right)\left(\alpha_{n}-\lambda_{1}\right)>0$ and $\lim \inf _{n \rightarrow \infty}\left(1-\alpha_{n}\right)\left(\alpha_{n}-\lambda_{2}\right) \beta_{n}>0$ we obtain from (32) that $\lim _{n \rightarrow \infty}\left\|x_{n}-v_{n}\right\|=0$ and $\lim _{n \rightarrow \infty}\left\|x_{n}-z_{n}\right\|=0$. Hence $p \in F(S) \cap F(T)$. It remains to show that $p$ is in $\operatorname{EP}(f)$. Now from (32)

$$
\left\|q-y_{n}\right\| \leq\left\|q-x_{n}\right\| .
$$

Also, using $u_{n}=T_{r_{n}} y_{n}$, Lemma 4 , and (35) we have

$$
\begin{aligned}
\left\|u_{n}-y_{n}\right\|^{2} & =\left\|T_{r_{n}} y_{n}-y_{n}\right\|^{2} \\
& \leq\left\|q-y_{n}\right\|^{2}-\left\|q-T_{r_{n}} y_{n}\right\|^{2} \\
& \leq\left\|q-x_{n}\right\|^{2}-\left\|q-T_{r_{n}} y_{n}\right\|^{2} \\
& =\left\|q-y_{n}\right\|^{2}-\left\|q-u_{n}\right\|^{2} .
\end{aligned}
$$

It then follows from (34) and (36) that

$$
\lim _{n \rightarrow \infty}\left\|u_{n}-y_{n}\right\|=0
$$

Consequently, we obtain from (31) and (37) that

$$
\lim _{n \rightarrow \infty}\left\|y_{n}-p\right\|=0
$$

From the assumption that $r_{n} \geq a>0$,

$$
\lim _{n \rightarrow \infty} \frac{\left\|u_{n}-y_{n}\right\|}{r_{n}}=0 .
$$

Since $u_{n}=T_{r_{n}} y_{n}$ implies

$$
f\left(u_{n}, y\right)+\frac{1}{r_{n}}\left\langle y-u_{n}, u_{n}-y_{n}\right\rangle \geq 0,
$$

we have from (A2) that

$$
\begin{aligned}
\frac{\left\|u_{n}-y_{n}\right\|^{2}}{r_{n}} & \geq \frac{1}{r_{n}}\left\langle y-u_{n}, u_{n}-y_{n}\right\rangle \geq-f\left(u_{n}, y\right) \\
& \geq f\left(y, u_{n}\right), \quad \forall y \in C .
\end{aligned}
$$

By taking limit as $n \rightarrow \infty$ of the above inequality and from (A4), (31), and (38) we have $f(y, p) \leq 0$, for all $y \in C$. Let $t \in(0,1)$ and for all $y \in C$, since $p \in C$, we have that $y_{t}=$ $t y+(1-t) p \in C$. Hence $f\left(y_{t}, p\right) \leq 0$. It follows from (A1) that

$$
\begin{aligned}
0 & =f\left(y_{t}, y_{t}\right) \leq t f\left(y_{t}, y\right)+(1-t) f\left(y_{t}, p\right) \\
& \leq t f\left(y_{t}, y\right) ;
\end{aligned}
$$

that is, $f\left(y_{t}, y\right) \geq 0$. Letting $t \downarrow 0$, from (A3) we obtain $f(p, y) \geq 0$ for all $y \in C$ so that $p \in \operatorname{EP}(f)$. Hence $y \in \mathbb{F}$.

Finally we show that $P=P_{\mathbb{F}} x_{0}$. By taking the limits as $n \rightarrow \infty$ in (23) we have

$$
\left\langle p-q, x_{0}-p\right\rangle \geq 0, \quad \forall q \in \mathbb{F} .
$$

It then follows from Lemma 5(i) that $p=P_{\mathbb{F}} x_{0}$. This completes the proof.

Corollary 8. Let $C$ be a nonempty closed convex subset of a real Hilbert space $H$, let $f: C \times C \rightarrow \mathbb{R}$ be a bifunction satisfying (A1)-(A4), and let $S, T: C \rightarrow P(C)$ be two strictly pseudocontractive mappings with contractive coefficients $\lambda_{1}$ and $\lambda_{2}$, respectively, such that $\mathbb{F}=F_{s}(T) \cap F_{s}(S) \cap \operatorname{EP}(f) \neq \emptyset$. Let $\left\{x_{n}\right\}$ be a sequence generated from an arbitrary $x_{0} \in C$ as follows:

$$
\begin{aligned}
& x_{0} \in H, \\
& C_{1}=C, \\
& x_{1}=P_{C} x_{0}, \\
& y_{n}=\alpha_{n} x_{n}+\left(1-\alpha_{n}\right)\left[\beta_{n} v_{n}+\left(1-\beta_{n}\right) z_{n}\right], \\
& u_{n} \in C \text { such that } \\
& F\left(u_{n}, y\right)+\frac{1}{r_{n}}\left\langle y-u_{n}, u_{n}-y_{n}\right\rangle \geq 0, \quad \forall y \in C, \\
& C_{n+1}=\left\{z \in C_{n}:\left\|z-u_{n}\right\|^{2} \leq\left\|z-x_{n}\right\|^{2}\right\}, \\
& x_{n+1}=P_{C_{n+1}} x_{0},
\end{aligned}
$$


where $v_{n} \in P_{T} x_{n}$ and $z_{n} \in P_{S} x_{n} .\left\{\alpha_{n}\right\}_{n=1}^{\infty}$ and $\left\{\beta_{n}\right\}_{n=1}^{\infty}$ are sequences in $[0,1]$ satisfying

(i) $\alpha_{n} \geq \max \left\{\lambda_{1}, \lambda_{2}\right\}$,

(ii) $\lim \inf _{n \rightarrow \infty}\left(1-\alpha_{n}\right)\left(1-\beta_{n}\right)\left(\alpha_{n}-\lambda_{1}\right)>0$ and $\lim \inf _{n \rightarrow \infty}\left(1-\alpha_{n}\right)\left(\alpha_{n}-\lambda_{2}\right) \beta_{n}>0$,

(iii) $\left\{r_{n}\right\} \subset[a, \infty)$ for some $a>0$.

Then $\left\{x_{n}\right\}$ converges strongly to $p \in P_{\mathbb{F}} x_{0}$.

Proof. The proof follows easily from Theorem 7.

\section{Competing Interests}

The author declares that there are no competing interests.

\section{References}

[1] F. O. Isiogugu, "Demiclosedness principle and approximation theorems for certain classes of multivalued mappings in Hilbert spaces," Fixed Point Theory and Applications, vol. 2013, article 61, 2013.

[2] C. E. Chidume, C. O. Chidume, N. Djitté, and M. S. Minjibir, "Convergence theorems for fixed points of multivalued strictly pseudocontractive mappings in Hilbert spaces," Abstract and Applied Analysis, vol. 2013, Article ID 629468, 10 pages, 2013.

[3] S. Reich and S. Sabach, "Three strong convergence theorems regarding iterative methods for solving equilibrium problems in reflexive Banach Spaces," Contemporary Mathematics, vol. 568, pp. 225-240, 2012.

[4] E. Blum and W. Oettli, "From optimization and variational inequalities to equilibrium problems," Mathematics Student, vol. 63, no. 1-4, pp. 123-145, 1994.

[5] A. Moudafi, "Second-order differential proximal methods for equilibrium problems," Journal of Inequalities in Pure and Applied Mathematics, vol. 4, article 18, 2003.

[6] P. L. Combettes and S. A. Hirstoaga, "Equilibrium programming in Hilbert spaces," Journal of Nonlinear and Convex Analysis, vol. 6, no. 1, pp. 117-136, 2005.

[7] W. Takahashi and K. Zembayashi, "Strong and weak convergence theorems for equilibrium problems and relatively nonexpansive mappings in Banach spaces," Nonlinear Analysis: Theory, Methods \& Applications, vol. 70, no. 1, pp. 45-57, 2009.

[8] F. O. Isiogugu, A. Udomene, and M. O. Osilike, "Approximation of com- mon solutions of equilibrium and fixed point problems for certain class of mappings in Hilbert spaces," Journal of the Nigerian Mathematical Society, vol. 30, pp. 179-194, 2011. 


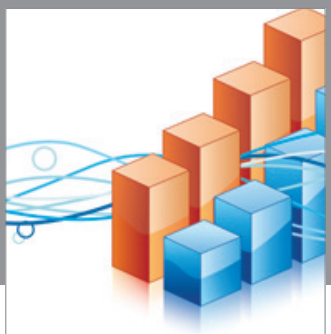

Advances in

Operations Research

vatem alat4

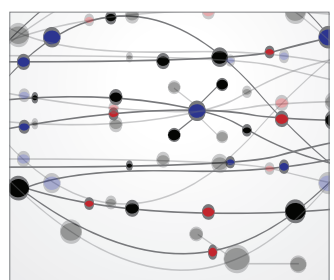

\section{The Scientific} World Journal
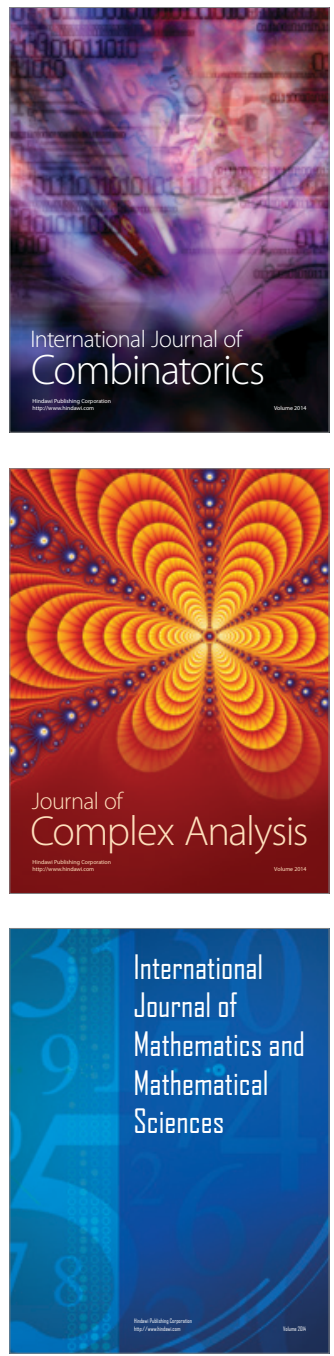
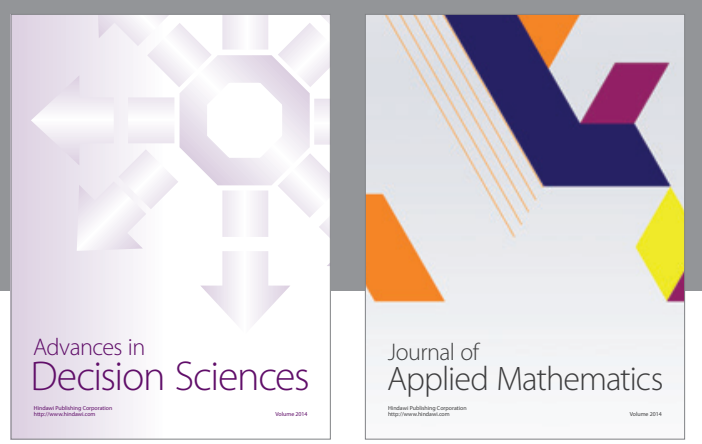

Algebra

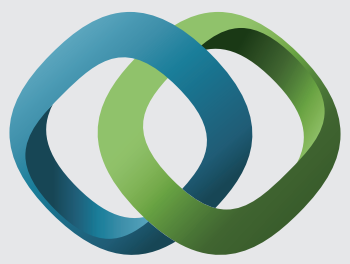

\section{Hindawi}

Submit your manuscripts at

http://www.hindawi.com
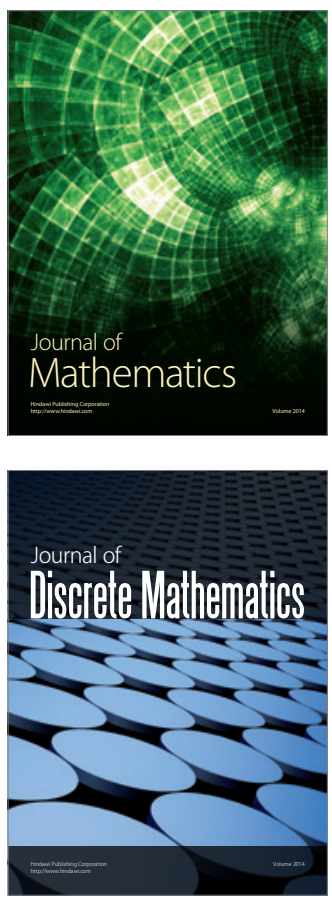

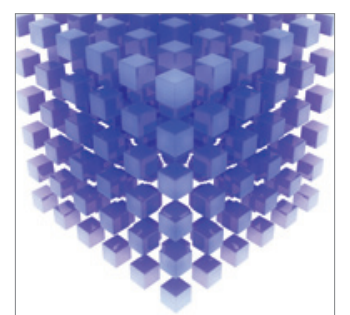

Mathematical Problems in Engineering
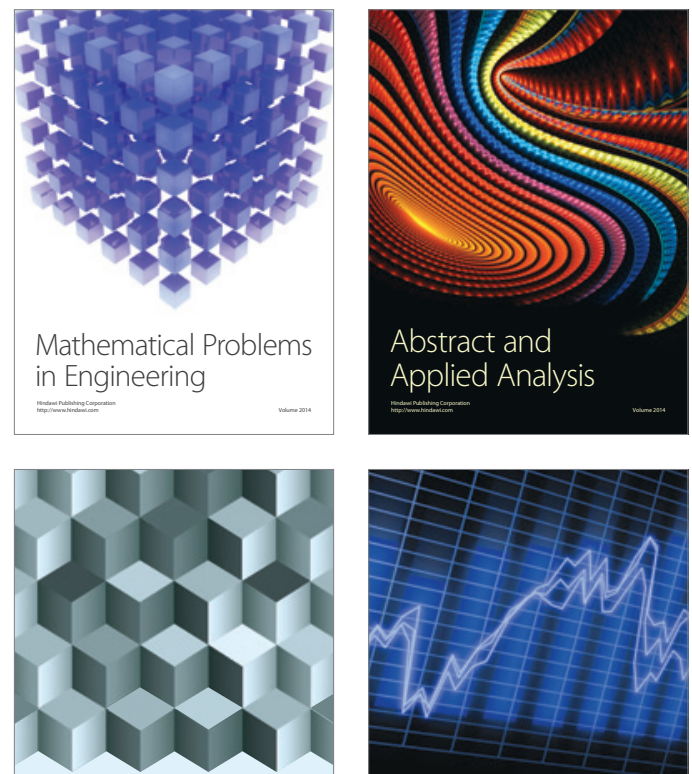

Journal of

Function Spaces

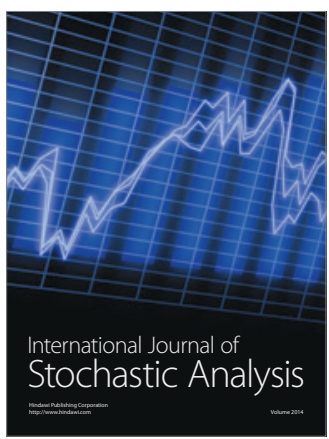

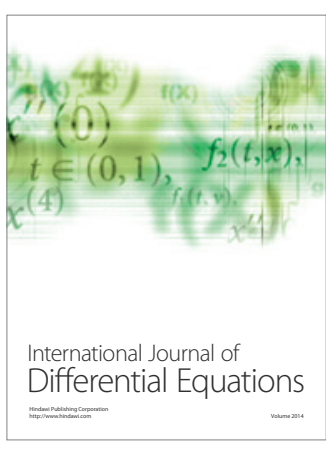
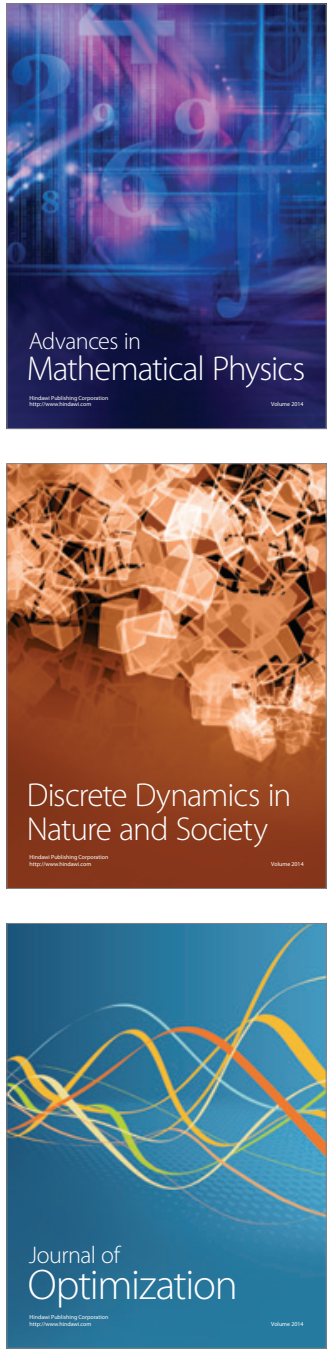